\title{
Does the incubator control mode influence outcomes of low-birth-weight neonates during the first days of life and at hospital discharge?
}

\author{
Pauline Décima ${ }^{1 *}$, Erwan Stéphan-Blanchard $^{1}$, André Léké $^{1,2}$, Loic Dégrugilliers ${ }^{1,2}$, \\ Stéphane Delanaud ${ }^{1}$, Jean-Pierre Libert ${ }^{1}$, Pierre Tourneux ${ }^{1,2}$ \\ ${ }^{1}$ Laboratory PériTox EA 4285-UMI 01 INERIS, Amiens, France; ${ }^{*}$ Corresponding Author: pauline.decima@u-picardie.fr \\ ${ }^{2}$ Neonatal Intensive Care Unit, North Universitary Hospital, Amiens, France.
}

Received 26 May 2013; revised 27 June 2013; accepted 15 July 2013

Copyright (C) 2013 Pauline Décima et al. This is an open access article distributed under the Creative Commons Attribution License, which permits unrestricted use, distribution, and reproduction in any medium, provided the original work is properly cited.

\section{ABSTRACT}

Background: The thermal environment surrounding neonates in closed incubators can be regulated via two different modes: skin servocontrol mode (SSC) and air temperature control mode (ATC). These produce different patterns of incubator air and infant body temperatures. Objective: To assess the effects of incubator control mode on clinical outcomes of low-birth-weightinfants during the first days of life and at hospital discharge. Methods: 52 low-birth-weight neonates were nursed over ten days in closed incubators functioning either with SSC mode $(n=$ $29)$, or with ATC mode $(n=23)$. Results: The anthropomorphic characteristics of the two groups of neonates were homogenous (gestational age $=29.4 \pm 1.4$ vs. $29.9 \pm 1.2$ weeks and birthweight $=1214 \pm 347$ vs. $1263 \pm 292 \mathrm{~g}$ in the SSC-group and the ATC-group, respectively) and the caregiving (energy and fluid intakes, ventilator assistance and drug administration) did not differ statistically. Daily means of incubator air temperature were similar in the SSC and the ATC-group, however, the SSC mode resulted in more variable incubator air temperature but more stable skin abdominal temperature whereas the reverse was found when using the ATC mode. Those differences had no impact on the body weight of the neonates or their clinical outcomes at hospital discharge which were not statistically different. Conclusion: The clinical outcomes do not differ depending on the incubator control mode after the first ten days of life and at hospital discharge.

Keywords: Clinical Outcomes; Preterm Neonates; Closed Incubators; Incubator Control Mode

\section{BACKGROUND}

Adults are able to maintain a constant core body temperature over a wide range of ambient thermal conditions. In contrast, the newborn infant can only achieve homeothermia over a much narrower range of ambient conditions. The preterm infant has even greater difficulty in maintaining core temperature as their thermal capability is exponentially correlated with gestational age [1]. During the first days of life, management of the thermal environment requires close attention in preterm infants who are particularly prone to both hyper- and hypothermia. The range of ambient temperatures, which an immature infant can maintain body temperature, with minimal energy expenditure, is very narrow $\left(36.5^{\circ} \mathrm{C}-37.5^{\circ} \mathrm{C}\right)$. As a result, maintaining the core body temperature by controlling the environmental temperature is an essential for survival and optimum body growth as well as for various physiological functions [2]. The optimal ambient temperature at which the infant should be nursed is defined as "the range of environmental temperature within which the metabolic rate is at a minimum and within which temperature regulation is achieved by non-evaporative physical processes alone".

Neonatal incubators currently use two types of temperature control, air temperature control (ATC) and skin servocontrol modes (SSC). SSC mode is designed to maintain the neonate's abdominal skin temperature constant, whereas the ATC mode is based on the control of 
the circulating incubator air temperature $\left(\mathrm{T}_{\mathrm{a}}\right)$. Abdominal skin temperature is used as an input signal since this parameter is assumed to be closely related to metabolic heat production. These 2 types of control modes produce different patterns of incubator air and infant body temperatures [3]. ATC seems to provide a more stable environment than SSC does [4] for thermal instability is due to repeated changes in infant skin temperature which result in repeated heating demands due to the error signal proportional to skin temperature changes. Heim [5] reported that the metabolic heat production of a 7 dayold-premature neonate (body mass $780 \mathrm{~g}$, gestational age 27 weeks) did not reach a steady state level, but body temperature oscillated following the incubator air temperature. An increase in energy metabolism of $42 \%$ over minimal values was found, whereas with a control of air temperature at $34^{\circ} \mathrm{C}$, these fluctuations only reached $18 \%$. Unfortunately, the effect of this difference in metabolism on body growth was not reported by these authors. Taking into account these observations, it is generally reported that the SSC mode should be used when the thermoregulatory system of neonates is fully efficient, but this remains to be proven in low-birth-weight infants.

It is well-known that the temperature management also influences infant outcomes [6], however, only a few studies have aimed to compare the impact of the 2 types of incubator control mode on these outcomes. Sinclair, in a meta-analysis [7] of two trials [8,9] used fatal events as an outcome (death, death by postnatal age period, death by birth weight group) and axillary temperature, as the only physiological parameter, pointed out that there was a very large decrease in death rate of low-birth-weight infants when using an incubator controlled from abdominal skin temperature kept at $36.0^{\circ} \mathrm{C}$ while no adverse biologic consequences of thermal stability were found. To the best of our knowledge, no other studies dealing with this problem are available in the literature. Thus, the purpose of the present study was to assess the effects of incubator control mode on clinical outcomes over the first days of life and at hospital discharge for low-birth-weight infants.

\section{PATIENTS AND METHODS}

Before the investigation, the study was approved by the local ethics committee and all parents provided written informed consent. All the neonates were studied in the neonatal intensive care unit (NICU) at Centre Hospitalier Universitaire Nord in Amiens (France) and nursed for 10 days in a closed incubator Satis + (Médipréma, France). Infants were eligible if they had been born within the past 12 hours, before 33 weeks of gestation and with an Apgar score of at least 5 at $10 \mathrm{~min}$. Infants were excluded if they had a major congenital abnormality and if they had to leave the NICU before the end of the study period. 52 neonates out of 56 recruited fulfilled these criteria. All infants were randomly assigned to one of the 2 incubator control modes: the SSC-group $(n=29)$ and the ATC-group $(n=23)$. All the neonates were nursed supine in incubator. The SSC mode was set to reach and maintain an abdominal skin temperature (Tabdo) of $36.8^{\circ} \mathrm{C}$ as recommended by the WHO [10]. The thermistor probe was taped between the xiphoïd process and the umbilicus. The incubator air temperature in the ATC-group was determined using PRETHERM ${ }^{\circledR}$ software [11] which is not integrated in the incubator. PRETHERM $^{\circledR}$ allows the calculation of incubator air temperature $\left(\mathrm{T}_{\mathrm{a}}\right)$ by taking into account the neonate's characteristics and the thermal insulation of any clothing. It was designed so that the value of incubator air temperature was calculated in order that the metabolic heat production defined by Chessex et al. [12] was minimal. Once calculated each day by the software, $\mathrm{T}_{\mathrm{a}}$ was set by the medical staff once daily. $\mathrm{T}_{\mathrm{a}}$, Tabdo and the relative air humidity $(\mathrm{RH})$ inside the incubator were recorded every second during the 10 days using PT 1000 probes for all temperatures (accuracy: $\pm 0.3^{\circ} \mathrm{C}$ ) and a capacitive humidity sensor for relative air humidity (accuracy: $\pm 10 \%$ ). The temperature in the room was kept around $25^{\circ} \mathrm{C}$ (relative air humidity $35 \%-50 \%$; air velocity lower than 0.2 $\mathrm{m} / \mathrm{s}$ ). From the first day of life (noted D0) to the $10^{\text {th }}$ day of life (last day of the study, D9), the neonate's weight and caregiving (energy intake, respiratory assistance and drug administration) were scored to describe the neonate's health status. At hospital discharge, we recorded the duration of hospitalization, the prevalence of bronchopulmonary dysplasia, the use of steroids and the occurrence of intra-ventricular hemorrhage. All these clinical outcomes were documented daily in patient medical records.

\section{STATISTICAL ANALYSIS}

Statview 5.0 software (SAS Institute Inc., USA) was used for the statistical analysis. The anthropomorphic characteristics and the daily outcomes were compared between the two groups using a parametric ANOVA analysis (F-values and the degree of freedom are indicated). When data were expressed as proportions, we used a chi-square test $\left(\chi^{2}\right.$-values and the degree of freedom are indicated). Data were expressed as mean $\pm 1 \mathrm{SD}$. The significance was set at 0.05 .

\section{RESULTS}

\subsection{Anthropomorphic Characteristics}

In the SSC-group, the neonates were $29.4 \pm 1.4$ weeks of gestational age, weighted $1217 \pm 347 \mathrm{~g}$ at birth, their head circumference was $26.4 \pm 2.2 \mathrm{~cm}$ and their height at birth was $36.7 \pm 3.3 \mathrm{~cm}$, their Apgar score at 5 min was 9 
$\pm 2,79 \%$ of them were appropriated-for-gestational age and $66 \%$ were male. In the ATC-group, the neonates were $29.9 \pm 1.2$ weeks of gestational age, weighted 1263 $\pm 292 \mathrm{~g}$ at birth, their head circumference was $27.0 \pm 1.6 \mathrm{~cm}$ and their height at birth was $37.6 \pm 2.7 \mathrm{~cm}$, their Apgar score at 5 min was $9 \pm 1,78 \%$ of them were appropriated-for-gestational age and 39\% were male. Table 1 shows that none of the anthropomorphic characteristics were statistically different between the two groups of neonates.

\subsection{Thermal Environment}

From D0 to D9, Figure 1 shows that the daily mean values of $T_{a}$ and HR (in the left panel), as well as the intra-day fluctuations of HR (in the right panel), did not differ between the 2 groups of neonates. In contrast, intra-day fluctuations of $T_{a}$ (in the right panel) were significantly lower in the ATC-group (range between $1.3^{\circ} \mathrm{C}$ and $\left.1.7^{\circ} \mathrm{C}\right)$ than in the SSC-group $\left(0.5^{\circ} \mathrm{C}-0.9^{\circ} \mathrm{C}\right)$.

\subsection{Abdominal Skin Temperature}

Figure 2 shows that Tabdo was significantly higher in the ATC-group $\left(37.0^{\circ} \mathrm{C}\right)$ than in the SSC-group $\left(36.7^{\circ} \mathrm{C}\right)$ at D0, D4, D5, D6, D7, D8 and D9. Intra-day fluctua tions of Tabdo were also statistically higher in the ATCgroup (range between $0.4^{\circ} \mathrm{C}$ and $0.5^{\circ} \mathrm{C}$ ) than in the SSCgroup $\left(0.2^{\circ} \mathrm{C}\right.$ to $\left.0.3^{\circ} \mathrm{C}\right)$.

\subsection{Caregiving}

Daily energy intakes were comparable between the SSC- and the ATC-groups from D0 to D9. Neonates received $81 \pm 12 \mathrm{kcal} \cdot \mathrm{kg}^{-1} \cdot \mathrm{j}^{-1}$ on average in the SSC-group and $85 \pm 12 \mathrm{kcal} \cdot \mathrm{kg}^{-1} \cdot \mathrm{j}^{-1}$ in the ATC-group $\left(\mathrm{F}_{1,46}=1.081\right.$, $\mathrm{p}=0.304)$. However, the daily energy intake increased slightly from D0 $\left(29 \pm 8 \mathrm{kcal} \cdot \mathrm{kg}^{-1} \cdot \mathrm{j}^{-1}\right.$ in the SSC-group and $29 \pm 10 \mathrm{kcal} \cdot \mathrm{kg}^{-1} \cdot \mathrm{j}^{-1}$ in the ATC-group, $\mathrm{F}_{1,46}=0.001$, $\mathrm{p}=0.972)$ to D9 $\left(109 \pm 24 \mathrm{kcal} \cdot \mathrm{kg}^{-1} \cdot \mathrm{j}^{-1}\right.$ in the SSCgroup and $113 \pm 22 \mathrm{kcal} \cdot \mathrm{kg}^{-1} \cdot \mathrm{j}^{-1}$ in the ATC-group, $\mathrm{F}_{1,46}=$ $0.434, \mathrm{p}=0.513$ ).

Daily fluid intake did not differ statistically between the SSC- and the ATC-groups from D0 to D7. Neonates received $112 \pm 32 \mathrm{ml} \cdot \mathrm{kg}^{-1} \cdot \mathrm{j}^{-1}$ on average in the SSCgroup and $111 \pm 25 \mathrm{ml} \cdot \mathrm{kg}^{-1} \cdot \mathrm{j}^{-1}$ in the ATC-group $\left(\mathrm{F}_{1,46}=\right.$ $0.004, p=0.952$ ). However, the daily energy intake was significantly higher at D8 in the SSC-group $(190 \pm 35$ $\left.\mathrm{ml} \cdot \mathrm{kg}^{-1} \cdot \mathrm{j}^{-1}\right)$ compared to in the ATC-group $(168 \pm 29$ $\left.\mathrm{ml} \cdot \mathrm{kg}^{-1} \cdot \mathrm{j}^{-1}, \mathrm{~F}_{1,46}=5.035, \mathrm{p}=0.030\right)$ and at $\mathrm{D} 9(186 \pm 21$ $\mathrm{ml} \cdot \mathrm{kg}^{-1} \cdot \mathrm{j}^{-1}$ in the SSC-group and $170 \pm 33$

Table 1. Anthropomorphic characteristics of the neonates divided into skin servocontrol-group (SSC) and air temperature control-group (ATC). Gestational age (GA, weeks), birthweight (g), head circumference $(\mathrm{cm})$, height at birth ( $\mathrm{cm}$ ) and the Apgar scores at 0,5 and $10 \mathrm{~min}$ of life are expressed as means $( \pm 1 \mathrm{SD})$, minimal and maximal values. Percentages quantify the number of Small-for-Gestational Age (SGA), Appropriate-for-Gestational Age (AGA), female and male neonates in each group. The middle column shows the statistical tests to compare the 2 groups of infants. NS $=$ Not Significant.

\begin{tabular}{|c|c|c|c|c|c|c|c|}
\hline & \multicolumn{7}{|c|}{ Anthropomorphic characteristics } \\
\hline & \multicolumn{3}{|c|}{$\mathrm{SSC}$} & \multirow{2}{*}{ Significance } & \multicolumn{3}{|c|}{ ATC } \\
\hline & Mean \pm 1 SD & Min & $\operatorname{Max}$ & & Mean \pm 1 SD & Min & Max \\
\hline GA (weeks) & $29.4 \pm 1.4$ & 26.0 & 31.3 & $\mathrm{~F}_{1,50}=1.972 ; \mathrm{p}=0.167 ; \mathrm{NS}$ & $29.9 \pm 1.2$ & 28.0 & 31.6 \\
\hline Birthweight (g) & $1217 \pm 347$ & 655 & 1980 & $\mathrm{~F}_{1,50}=0.259 ; \mathrm{p}=0.613 ; \mathrm{NS}$ & $1263 \pm 292$ & 750 & 1800 \\
\hline Head circumference $(\mathrm{cm})$ & $26.4 \pm 2.2$ & 22.0 & 30.0 & $\mathrm{~F}_{1,49}=1.180 ; \mathrm{p}=0.283 ; \mathrm{NS}$ & $27.0 \pm 1.6$ & 24.0 & 29.5 \\
\hline Height at birth (cm) & $36.7 \pm 3.3$ & 30.0 & 43.0 & $\mathrm{~F}_{1,50}=1.000 ; \mathrm{p}=0.322 ; \mathrm{NS}$ & $37.6 \pm 2.7$ & 32.0 & 42.0 \\
\hline Apgar at $0 \mathrm{~min}$ & $8 \pm 3$ & 1 & 10 & $\mathrm{~F}_{1,45}=0.003 ; \mathrm{p}=0.958 ; \mathrm{NS}$ & $8 \pm 2$ & 3 & 10 \\
\hline Apgar at $5 \mathrm{~min}$ & $9 \pm 2$ & 8 & 10 & $\mathrm{~F}_{1,45}=0.180 ; p=0.674 ; \mathrm{NS}$ & $9 \pm 1$ & 7 & 10 \\
\hline \multirow[t]{3}{*}{ Apgar at $10 \mathrm{~min}$} & $10 \pm 1$ & 8 & 10 & $\mathrm{~F}_{1,45}=0.031 ; \mathrm{p}=0.860 ; \mathrm{NS}$ & $10 \pm 1$ & 8 & 10 \\
\hline & \multicolumn{3}{|c|}{$\mathrm{SSC}$} & & \multicolumn{3}{|c|}{ ATC } \\
\hline & \multicolumn{3}{|c|}{$\%$ of the group } & & \multicolumn{3}{|c|}{$\%$ of the group } \\
\hline SGA & \multicolumn{3}{|c|}{21} & \multirow{2}{*}{$\chi_{1}^{2}=3.594 ; \mathrm{p}=0.058 ; \mathrm{NS}$} & \multicolumn{3}{|c|}{22} \\
\hline AGA & \multicolumn{3}{|c|}{79} & & \multicolumn{3}{|c|}{78} \\
\hline Female & \multicolumn{3}{|c|}{34} & \multirow[t]{2}{*}{$\chi_{1}^{2}=0.008 ; \mathrm{p}=0.927 ; \mathrm{NS}$} & \multicolumn{3}{|c|}{61} \\
\hline Male & & 66 & & & \multicolumn{3}{|c|}{39} \\
\hline
\end{tabular}




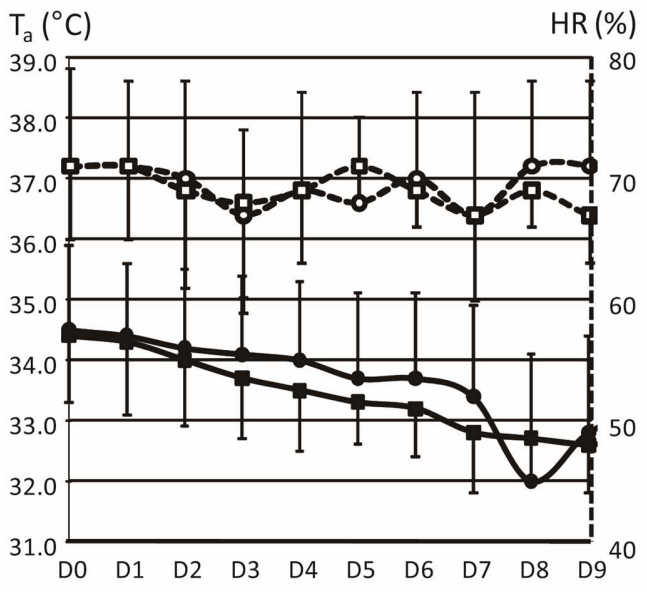

(a)
$R(\%) \quad$ Intra-day fluctuations $T_{a}\left({ }^{\circ} \mathrm{C}\right) \quad H R(\%)$

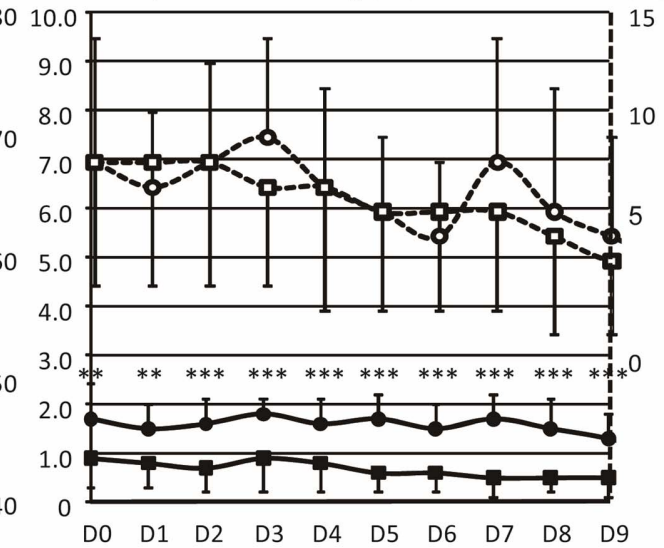

(b)

Figure 1. Thermal environment. The preterm infants were divided into the skin servocontrol-group (SSC, circles) and the air temperature control-group (ATC, squares). Daily values (mean $\pm 1 \mathrm{SD}$ ) of incubator air temperatures $\left(\mathrm{T}_{\mathrm{a}},{ }^{\circ} \mathrm{C}\right.$, solid lines and closed symbols) and relative air humidity (HR, \%, dashed lines and open symbols) are represented on the left side of the figure. Intra-day fluctuations of $\mathrm{T}_{\mathrm{a}}\left({ }^{\circ} \mathrm{C}\right.$, full lines and symbols) and relative air humidity (HR, \%, hatched lines and empty symbols) are represented on the right side of the figure. All the values are represented from the first day of life (D0) to the last day (D9) of the study. Values are mean \pm 1 SD. ${ }^{* *} \mathrm{p}<0.01,{ }^{* * *} \mathrm{p}<0.001$.

Daily Tabdo $\left({ }^{\circ} \mathrm{C}\right)$

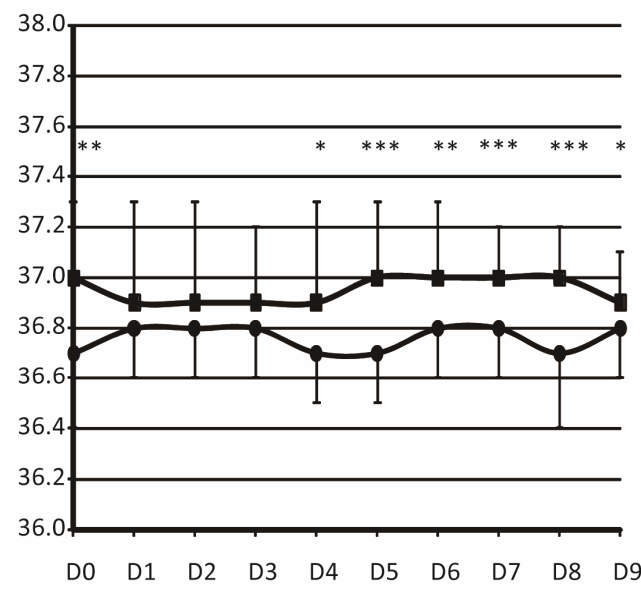

(a)
Intra-day fluctuations Tabdo $\left({ }^{\circ} \mathrm{C}\right)$

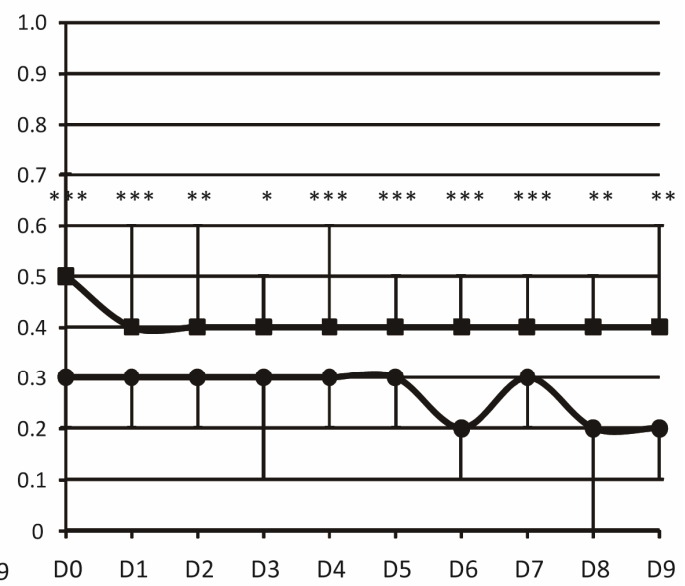

(b)

Figure 2. Abdominal skin temperature. The infants are divided into: skin servocontrol-group (SSC, and air temperature control-group (ATC, $\square$ ). Daily values of abdominal skin temperature $\left(\right.$ Tabdo, ${ }^{\circ} \mathrm{C}$ ) are represented in the left panel and intra-day fluctuations are represented on the right side of the figure. All the values are represented from the first day of life (D0) to the last day (D9) of the study. Values are mean \pm 1 SD. ${ }^{*} \mathrm{p}<0.05,{ }^{* *} \mathrm{p}<0.01,{ }^{* * *} \mathrm{p}<0.001$.

$\mathrm{kcal} \cdot \mathrm{kg}^{-1} \cdot \mathrm{j}^{-1}$ in the ATC-group, $\left.\mathrm{F}_{1,46}=4.161, \mathrm{p}=0.047\right)$.

Table 2 shows that the number of days with oxygen assistance or artificial ventilation as well as the percentages of neonates under oxygen assistance or artificial ventilation or treated with cardioactive drugs at D6 and D9 were not different between the 2 groups. It should noted that caffeine was administered more frequently in the ATC-group than in the SSC-group at D9 $\left(\chi_{1}^{2}=\right.$ 4.205, $\mathrm{p}=0.041)$.

\subsection{Neonate's Weight}

As shown in Table 3, 6 days were necessary to recover birthweight ( $6 \pm 4$ vs. $6 \pm 5$ days in the SSC and the ATC-group, respectively), this value was similar in the 2 groups $\left(\mathrm{F}_{1,47}=0.059, \mathrm{p}=0.810\right)$. The maximal loss of weight did not differ between the SSC and the ATC-group $(-6.2 \pm 3.5$ vs. $-5.7 \% \pm 3.5 \%$, respectively; $\left.\mathrm{F}_{1,47}=0.290, \mathrm{p}=0.593\right)$. The weights at D6 and at D9 were not statistically different between the SSC- and the 
Table 2. Ventilatory and medication caregiving. The infants were divided into skin servocontrol-group (SSC) and air temperature control-group (ATC). The number of days (d) under oxygen assistance or artificial ventilation are expressed as means ( \pm 1 SD), minimal and maximal values are also indicated. The percentages of neonates of each group under oxygen assistance, artificial ventilation, caffeine and cardioactive drugs are documented after the first week of life (D6) and at the end of the study (D9). The middle column shows statistical tests to compare the 2 incubator control modes. NS $=$ Non Significant, ${ }^{*} \mathrm{p}<0.05$.

\begin{tabular}{|c|c|c|c|c|c|c|c|}
\hline & \multicolumn{7}{|c|}{ Ventilatory and drug caregiving } \\
\hline & \multicolumn{3}{|c|}{$\mathrm{SSC}$} & \multirow{2}{*}{ Significance } & \multicolumn{3}{|c|}{ ATC } \\
\hline & Mean \pm 1SD & Min & Max & & Mean \pm 1 SD & Min & $\operatorname{Max}$ \\
\hline Oxygen assistance (d/study) & $4 \pm 4$ & 0 & 10 & $\mathrm{~F}_{1,50}=0.124 ; \mathrm{p}=0.727 ; \mathrm{NS}$ & $4 \pm 3$ & 0 & 10 \\
\hline \multirow[t]{3}{*}{ Artificial ventilation (d/study) } & $7 \pm 3$ & 1 & 10 & $F_{1,50}=3.846 ; p=0.706 ; N S$ & $5 \pm 3$ & 2 & 10 \\
\hline & \multicolumn{3}{|c|}{$\mathrm{SSC}$} & & \multicolumn{3}{|c|}{ ATC } \\
\hline & \multicolumn{3}{|c|}{$\%$ of the group } & & \multicolumn{3}{|c|}{$\%$ of the group } \\
\hline Oxygen assistance at D6 & \multicolumn{2}{|c|}{48} & \multicolumn{2}{|r|}{$\chi_{1}^{2}=0.957 ; p=0.328 ; \mathrm{NS}$} & \multicolumn{3}{|c|}{35} \\
\hline Oxygen assistance at D9 & \multicolumn{2}{|c|}{31} & & $\chi_{1}^{2}=0.085 ; \mathrm{p}=0.770 ; \mathrm{NS}$ & \multicolumn{3}{|c|}{26} \\
\hline Artificial ventilation at D6 & \multicolumn{2}{|c|}{48} & & $\chi_{1}^{2}=1.696 ; p=0.193 ; \mathrm{NS}$ & \multicolumn{3}{|c|}{30} \\
\hline Artificial ventilation at D9 & \multicolumn{2}{|c|}{31} & & $\chi_{1}^{2}=2.105 ; \mathrm{p}=0.147 ; \mathrm{NS}$ & \multicolumn{3}{|c|}{13} \\
\hline Caffeine at D6 & \multicolumn{2}{|c|}{90} & & $\chi_{1}^{2}=0.650 ; p=0.420 ; \mathrm{NS}$ & \multicolumn{3}{|c|}{96} \\
\hline Caffeine at D9 & \multicolumn{2}{|c|}{83} & & $\chi_{1}^{2}=4.205 ; p=0.041 ;$ & \multicolumn{3}{|c|}{96} \\
\hline Cardioactive drug at D6 & \multicolumn{2}{|c|}{55} & & $\chi_{1}^{2}=0.702 ; \mathrm{p}=0.402 ; \mathrm{NS}$ & \multicolumn{3}{|c|}{43} \\
\hline Cardioactive drug at D9 & \multicolumn{2}{|c|}{45} & & $\chi_{1}^{2}=1.018 ; \mathrm{p}=0.313 ; \mathrm{NS}$ & \multicolumn{3}{|c|}{57} \\
\hline
\end{tabular}

Table 3. Neonate's weight. The preterm infants were divided into skin servocontrol-group (SSC) and air temperature control-group (ATC). The number of days (d) to recover the birthweight, the maximal loss of weight (\%), and the weight (g) after the first week (D6) and at the end of the study (D9) are listed. Mean ( \pm 1 SD), minimal and maximal values are indicated. The middle column shows the statistical tests to compare the 2 incubator control modes. NS = Non Significant.

\begin{tabular}{|c|c|c|c|c|c|c|c|}
\hline & \multicolumn{7}{|c|}{ Neonate's weight } \\
\hline & \multicolumn{3}{|c|}{ SSC } & \multirow{2}{*}{ Significance } & \multicolumn{3}{|c|}{ ATC } \\
\hline & Mean \pm 1 SD & Min & Max & & Mean \pm 1 SD & Min & Max \\
\hline Recovery of birthweight (d) & $6 \pm 4$ & 1 & 11 & $\mathrm{~F}_{1,47}=0.059 ; \mathrm{p}=0.810 ; \mathrm{NS}$ & $6 \pm 5$ & 1 & 11 \\
\hline Maximal loss of weight (\%) & $-6.2 \pm 3.5$ & -6.2 & 5.7 & $\mathrm{~F}_{1,47}=0.290 ; \mathrm{p}=0.593 ; \mathrm{NS}$ & $-5.7 \pm 3.5$ & -6.2 & 5.8 \\
\hline Weight at D6 (g) & $1163 \pm 274$ & 670 & 1860 & $\mathrm{~F}_{1,50}=0.914 ; \mathrm{p}=0.344 ; \mathrm{NS}$ & $1231 \pm 232$ & 810 & 1600 \\
\hline Weight at D9 (g) & $1208 \pm 282$ & 668 & 1830 & $F_{1,49}=1.662 ; p=0.203 ; N S$ & $1304 \pm 240$ & 840 & 1690 \\
\hline
\end{tabular}

ATC-group.

\subsection{Clinical Outcomes at Hospital Discharge}

None of the long-term outcomes at hospital discharge (Table 4) differed statistically between the SSC- and the ATC-group: the time at hospital and in NICU level III and II were similar, the time of ventilatory assistance (21 \pm 13 vs. $17 \pm 10$ days, in the SSC-group and in the ATCgroup, respectively; $\mathrm{F}_{1,37}=3.950, \mathrm{p}=0.054$ ), bronchopulmonary dysplasia and cerebral intraventricular hemorrhage were diagnosed in same proportions in both groups and the use of corticosteroids did not differ between the two groups.

\section{DISCUSSION}

Thermal management has been termed the cornerstone of neonatal care [13]. Provision of a supportive thermal environment reduces metabolic requirements and is a basic objective of neonatal care [14]. The use of one incubator control mode compared to the other one is correlated to a huge variability of practice and the choice relies on clinical habits more than the literature [15]. In the present study, the incubator air temperature required to maintain abdominal skin temperature at $36.8^{\circ} \mathrm{C}$ ranged between $34.5^{\circ} \mathrm{C}$ (D0) to $32.8^{\circ} \mathrm{C}$ (D9) and did not differ from the values recorded using the air temperature control mode. Only the intra-day fluctuations of air temperature differed and were of larger magnitudes with the skin servocontrol mode.

In previous studies, Chessex et al. [4], Ducker et al. [16], Heim [5], Thomas and Burr [3] showed that differing thermal environments were measured in incubators with skin servocontrol mode compared to air temperature control modes. We confirm these results. Skin servocontrol 
Table 4. Clinical outcomes at hospital discharge. The infants were divided into skin servocontrol-group (SSC) and air temperature control-group (ATC). Time (in neonatal intensive care units NICU levels III and II, at hospital and of ventilatory assistance) (in days, d) are mean values $( \pm 1 \mathrm{SD})$. Diagnosis of bronchopulmonary dysplasia and corticosteroid treatments, diagnosis of cerebral intraventricular hemorrhage (IVH) and stage (from 1 to 3, 3 was the most severe clinical cases) are indicated in percentages (\%). The middle column shows the statistical tests to compare the 2 modes of regulation. NS = Non Significant.

\begin{tabular}{|c|c|c|c|}
\hline & \multicolumn{3}{|c|}{ Long-term outcome at hospital discharge } \\
\hline & SSC & Significance & ATC \\
\hline Time (d) in NICU level III & $19 \pm 13$ & $\mathrm{~F}_{1,50}=2.571 ; \mathrm{p}=0.115 ; \mathrm{NS}$ & $14 \pm 10$ \\
\hline Time (d) in NICU level II & $14 \pm 16$ & $\mathrm{~F}_{1,50}=0.041 ; \mathrm{p}=0.841 ; \mathrm{NS}$ & $13 \pm 12$ \\
\hline Time (d) at hospital & $33 \pm 21$ & $\mathrm{~F}_{1,50}=1.505 ; \mathrm{p}=0.226 ; \mathrm{NS}$ & $26 \pm 15$ \\
\hline Total time of ventilatory assistance (d) & $21 \pm 13$ & $\mathrm{~F}_{1,37}=3.950 ; \mathrm{p}=0.054 ; \mathrm{NS}$ & $17 \pm 10$ \\
\hline Diagnosis of bronchodysplasia (\%/group) & 34 & $\chi_{1}^{2}=2.105 ; p=0.147 ; \mathrm{NS}$ & 13 \\
\hline Use of steroids (\%/group) & 7 & $\chi_{1}^{2}=0.000 ; \mathrm{p}>0.999 ; \mathrm{NS}$ & 4 \\
\hline Diagnosis IVH (\%/group) & 31 & $\chi_{1}^{2}=0.404 ; p=0.525 ; \mathrm{NS}$ & 43 \\
\hline IVH stage 1 (\%/group) & 44 & & 70 \\
\hline IVH stage 2 (\%/group) & 44 & $\chi_{1}^{2}=1.436 ; p=0.488 ; \mathrm{NS}$ & 20 \\
\hline IVH stage 3 (\%/group) & 12 & & 10 \\
\hline
\end{tabular}

mode resulted in more variable incubator air temperatures $\left(1.54^{\circ} \mathrm{C}\right.$ on average daily throughout our study) but more stable abdominal temperature $\left(0.27^{\circ} \mathrm{C}\right.$ on average daily along our study). In contrast, the reverse is found with air temperature control mode: incubator air temperature varied by $0.65^{\circ} \mathrm{C}$ on average daily across our study and abdominal temperature by $0.41^{\circ} \mathrm{C}$. In the present study, when using skin servocontrol mode, the fluctuations of air temperature were larger than $1.3^{\circ} \mathrm{C}$ (range between $1.3^{\circ} \mathrm{C}$ and $1.8^{\circ} \mathrm{C}$ ) which is close to the values reported by Chessex et al. [4] $\left(2^{\circ} \mathrm{C}\right)$ using double walled incubators. With this mode, the delay in switching off the heater reduces the fluctuations of body temperature and maintaining the reference $\left(36.8^{\circ} \mathrm{C}\right)$ in a narrow range, but exposes the neonate to an unstable thermal environment. Most of the studies reported above are primarily focused on thermophysiological parameters. Thus, as previously reported in the introduction, Heim [5] pointed out that oxygen consumption was increased when using the skin servocontrol mode. Ducker et al. [16] reported that with air temperature control mode, abdominal skin and toe temperatures showed much less variation compared with the skin servocontrol mode. Bell and Rios [17] found no difference in body heat storage between the 2 control modes. Using skin servocontrol mode, due to the thermal instability, it cannot be discounted that neonates suffer from thermal stress or discomfort. It can be suggested that variations in incubator air temperature could trigger apneic events [18] by thermal simulation of specialized receptors in the larynx which modulate respiratory control but this remains questionable. We showed an administration of caffeine at D9 significatively more important in the ATC-group than in the SSC-group but the interpretation of this observation remains hazardous as it is not correlated to any long-term respiratory outcomes.

Few studies have taken into consideration the outcomes of preterm neonates when nursed with different incubator control modes. Sinclair [7] showed a decrease in death rate related to servo-control of abdominal skin temperature at $36^{\circ} \mathrm{C}$, that is lower than the value recommended by the WHO [10]. In our experimental conditions, caregiving and growth parameters did not differ between the two incubator control modes. The mean values of incubator air temperature are equivalent in both groups. Whatever the type of control mode used, neonates were nursed at thermoneutrality which allows optimum body growth and enhances better health resulting in the same caregiving and in similar term outcomes at hospital discharge, except daily fluid intakes at D8 and D9 which were higher in the SSC-group than in the ATC-group without being related to the neonate's body mass or any long-term outcomes. It does not seem that the air fluctuations observed when using the skin servocontrol mode are large enough and the cycles long enough to cause any deleterious effects on the various parameters analysed in the present study.

One of the limitations of this study was that only one type of incubator was used, so the research should be extended to all marketed devices. Furthermore, the patterns of incubator air and neonate body temperatures during caregiving procedures are also of importance, it would be of interest to study the patterns of temperature change during infant care periods between the two modes of control. Thomas [19] and Deguines et al. [20] have shown that, following caregiving activities, these patterns differed significantly over time as a function of incubator control mode and of the type of intervention. 
In addition, Deguines [20] also showed that incubator air temperature increased significantly when using the skin servocontrol mode while they showed little change when using the air temperature control mode. They also reported that skin abdominal temperature was reduced with ATC mode, but increased with SSC mode. However, those studies were only carried out for few days, and it would be interesting to analyse outcomes when neonates are nursed over long periods of time or during all their stay in closed incubators. The question remains whether a control system which constrains an infant's skin temperature so that it is always $36.8^{\circ} \mathrm{C}$ delays the neonate's thermoregulatory capabilities or whether the system should tolerate variation around this temperature to elicit an adaptation processes to prepare for when neonates were placed outside incubator, it should be investigated in the future. Last but not least, we did our analysis on the entire population of neonates in each group because the numbers of specific neonates were too small (for instance: 5 small-for gestational age neonates out of 23 in the ATC-group and 6 out of 29 in the SSC-group). However, specific investigations regarding the gestational age and the birthweight should be carried out in further studies. Indeed, small-for-gestational age neonates and/or neonates less than 28 weeks of gestational age represent an important proportion of the NICU population and a highly vulnerable population whose clinical outcomes and especially morbidity and mortality could be more sensitive to thermal environment induced by the choice of the incubator control mode. This could lead to a major advance to improve thermal caregiving of extremely low-birth-weight neonates.

\section{CONCLUSION}

Clinical outcomes of low-birth-weight neonates, nursed in closed incubators do not differ depending on the incubator control mode after the first ten days of life and at hospital discharge. However, further investigations crucially need to be carried out on a highly vulnerable and specific population of small-for-gestational age neonates and/or less than 28 weeks of gestational age.

\section{ACKNOWLEDGEMENTS}

We would like to sincerely thank all the parents and neonates for their participation, the devoted staff in the NICU at Centre Hospitalier Universitaire Nord of Amiens and the French National Research Agency's (ANR) which funded our work (TecSan Program, PRETHERM project: ANR-08-TecSan-016).

\section{REFERENCES}

[1] Dollberg, S., Demarini, S., Donovan, E.F. and Hoath, S.B. (2000) Maturation of thermal capabilities in preterm infants. Journal of Perinatology, 17, 47-51.
[2] Glass, L., Silverman, W.A. and Sinclair, J.C. (1968) Effect of thermal environment on cold resistance and growth of small infants after the first week of life. Pediatrics, 41, 1033-1046.

[3] Thomas, K.A. and Burr, R. (1999) Preterm infant thermal care: Differing thermal environments produced by air versus skin servo-control incubators. Journal of Perinatology, 19, 264-270.

[4] Chessex, P., Blovet, S. and Vaucher J. (1988) Environmental control in very low birth weight infants (less than 1000 grams) cared for in double walled incubators. Journal of Pediatrics, 113, 373-380.

[5] Heim, T. (1981) Homeothermy and its metabolic cost. In: Davis and Dobbing, Eds., Scientific Foundations of Paediatrics, Heinemann, London, 91-128.

[6] Richardson, D.K., Shah, B.L., Frantz, I.D., Bednarek, F., Rubin, L.P. and McCormick, M.C. (1999) Perinatal risk and severity of illness in newborns at 6 neonatal intensive care units. The American Journal of the Medical Sciences, 89, 511-516.

[7] Sinclair, J.C. (2008) Servo-control for maintaining abdominal skin temperature at $361 \mathrm{C}$ in low birth weight infants. Cochrane Database of Systematic Reviews, 2, Article ID: CD001074.

[8] Buetow, K.C. and Klein, S.W. (1964) Effect of maintenance of "normal" skin temperature on survival of infants of low birth weight. Pediatrics, 34, 163-170.

[9] Day, R.L., Caliguiri, L., Kamenski, C. and Ehrlich, F. (1964) Body temperature and survival of premature infants. Pediatrics, 34, 171-181.

[10] World Health Organization (2008) Thermal protection of the newborn. A practical guide WHO. Department of Reproductive Health and Research (RHR), Geneva.

[11] Décima, P., Dégrugilliers, L., Delanaud, S., Stéphan-Blanchard, E., Vanhée, J.L. and Libert, J.P. (2012) Design of a software for assessing thermoneutrality in closed incubators for preterm neonates (PRETHERM project). IRBM, 33, 48-54.

[12] Chessex, P., Reichman, B.L., Verellen, G.J., Putet, G., Smith, J.M., Heim, T. and Swyer, P.R. (1981) Influence of postnatal age, energy intake, and weight gain on energy metabolism in the very low-birth-weight infant. Journal of Pediatrics, 99, 761-766.

[13] Narendran, V. and Hoath, S.B. (1999) Thermal management of the low birth weight infant: A cornerstone of neonatology. Journal of Pediatrics, 134, 529-531.

[14] Graven, S.N., Bowen, F.W., Brooten, D., Eaton, A., Graven, M.N., Hack, M., Hall, L.A., Hansen, N., Hurt, H., Kavalhuna, R., et al. (1992) The high-risk infant environment. Part 1. The role of the neonatal intensive care unit in the outcome of highrisk infants. Journal of Perinatology, 12, 164-172.

[15] Deguines, C., Décima, P., Pelletier, A., Dégrugilliers, L., Ghyselen, L. and Tourneux, P. (2012) Variations in incubator temperature and humidity management: A survey of current practice. Acta Paediatrica, 101, 230-235.

[16] Ducker, D.A., Lyon, A.J., Roussel, R.R., Bass, C.A. and Mc Intosh, N. (1985) Incubator temperture control on the 
very-low-birth-weight infants. Archives of Disease in Childhood, 60, 902-907.

[17] Bell, E.F. and Rios, G.R. (1983) Air versus skin temperature servocontrol of infant incubators. Journal of Pediatrics, 103, 954-959.

[18] Perlstein, P.H., Edwards, N.K. and Sutherland, J.M. (1970) Apnea in premature infants and incubator-air-temperature changes. The New England Journal of Medicine, 282, 461-466.
[19] Thomas, K.A. (2003) Preterm infant thermal responses to caregiving differ by incubator control mode. Journal of Perinatology, 23, 640-645.

[20] Deguines, C., Dégrugilliers, L., Ghyselen, L., Chardon, K., Bach, V. and Tourneux, P. (2013) Impact of nursing care on temperature environment in preterm newborns nursed in closed convective incubators. Acta Paediatrica, 102, e96-e101. 